\title{
Actividad antiinflamatoria in vitro de los extractos etanólico y hexánico de tallos de Cuscuta jalapensis Schltdl.
}

\author{
In vitro anti-inflammatory activity of the ethanolic \\ and hexanic extracts of Cuscuta jalapensis Schltdl.'s stems
}

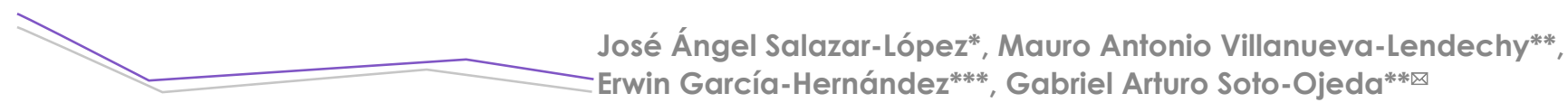

Salazar-López, J. A., Villanueva-Lendechy, M. A., García-Hernández, E., \& Soto-Ojeda, G. A. (2018). Actividad antiinflamatoria in vitro de los extractos etanólico y hexánico de tallos de Cuscuta jalapensis Schltdl. Investigación y Ciencia de la Universidad Autónoma de Aguascalientes, 26(75), 20-27.

RESUMEN

En este trabajo se evaluó la actividad antiinflamatoria in vitro del extracto etanólico y hexánico de Cuscuta jalapensis Schltdl. mediante el modelo de estabilidad de la membrana del eritrocito frente a dos agentes inductores de hemólisis, que fueron solución salina hipotónica y calor. Se realizó un tamiz fitoquímico para determinar las familias de metabolitos secundarios presentes en ambos extractos, se encontraron principalmente alcaloides y flavonoides. Posteriormente se realizó una curva concentraciónrespuesta de la actividad antiinflamatoria, partiendo de 50, 100, 200 y $400 \mu \mathrm{g} / \mathrm{ml}$ de ambos extractos, empleando como control farmacológico indometacina $100 \mu \mathrm{g} / \mathrm{ml}$. Los resultados indicaron que todas las concentraciones ensayadas de los diferentes extractos disminuyeron la hemólisis $y$,

Palabras clave: antiinflamatorio; estabilidad de la membrana; eritrocito; lisosoma; extracto.

Keywords: anti-inflammatory; membrane stability; erythrocyte; lysosome; extract.

Recibido: 22 de octubre de 2017, aceptado: 13 de junio de 2018

* División de Biología, Instituto Tecnológico Superior de Zacapoaxtla. Carretera Acuaco-Zacapoaxtla km 8, Col. Totoltepec, C. P. 73680 Zacapoaxtla, Puebla, México. Correo electrónico: marelyz_tc97@ hotmail.com

** Facultad de Química Farmacéutica Biológica, Universidad Veracruzana Circuito Gonzalo Aguirre Beltrán s/n, Zona Universitaria, C. P. 91000, Xalapa, Veracruz, México. Correo electrónico: mvillanueva@uv.mx; gsoto@uv.mx

*** Departamento de Posgrado e Investigación, División de Mecatrónica, Instituto Tecnológico Superior de Zacapoaxtla. Carretera AcuacoZacapoaxtla km 8, Col. Totoltepec, C. P. 73680, Zacapoaxtla, Puebla México. Correo electrónico: erwin.garcia@live.itsz.edu.mx

$\bowtie$ Autor para correspondencia por tanto, produjeron un efecto estabilizador de la membrana. Para la evaluación con solución salina hipotónica el extracto etanólico tuvo un efecto igual a indometacina $100 \mu \mathrm{g} / \mathrm{ml}$, las concentraciones del extracto hexánico mostraron una menor actividad antiinflamatoria en esta prueba; por otra parte, en la hemólisis con calor ambos extractos tuvieron efectos antiinflamatorios iguales y fueron mayores a los de indometacina. Estos resultados indican que los extractos de C. jalapensis presentan actividad antiinflamatoria in vitro siendo mejor el extracto etanólico, por lo que es factible seguir investigándola en modelos animales para profundizar en relación con sus efectos antiinflamatorios.

ABSTRACT

In this work, the in vitro anti-inflammatory activity of ethanolic and hexanic extracts of Cuscuta jalapensis Schltdl. was evaluated by using the erythrocyte membrane stability model against two agents inducing hemolysis, the hypotonic saline solution and heat. A phytochemical sieve was used to determine the families of secondary metabolites present in both extracts being alkaloids and flavonoid principally. A concentration response curve of the antiinflammatory activity was drawn, starting from 50 , 100, 200 and $400 \mu \mathrm{g} / \mathrm{ml}$, of both extracts, using 100 $\mathrm{\mu g} / \mathrm{ml}$ indomethacin as the pharmacological control. The results indicated that all tested concentrations of the different extracts decreased hemolysis and therefore produced a membrane stabilizing effect. For evaluation with hypotonic saline the ethanolic extract had an effect equal to indimetacin $100 \mu \mathrm{g} /$ 
$\mathrm{ml}$, the concentrations of the hexane extract showed a lower anti-inflammatory activity in this test; on the other hand, in hemolysis with heat, both extracts had similar anti-inflammatory effects and were greater than those of indomethacin. These results indicate that the extracts of $C$. jalapensis present anti-inflammatory activity in vitro being better the ethanolic extract, reason why it is feasible to continue investigating it in animal models to deepen in relation to its anti-inflammatory effects.

\section{INTRODUCCIÓN}

Las enfermedades inflamatorias son un problema de salud a nivel mundial (Gómez Velásquez \& Posada Tabares, 2013). Estas se originan por un proceso bioquímico debido a diversos factores endógenos y exógenos. De hecho, cualquier fenómeno inmunológico capaz de afectar la estabilidad del sistema puede ser considerado como estresante y el proceso que genera es denominado estrés inflamatorio (Sánchez, Sirera, Peiró, \& Palmero, 2008). Existen diversos medicamentos para la inflamación; sin embargo, algunos pueden tener reacciones indeseadas como irritabilidad gástrica, lo que puede limitar su uso (Velásquez Gómez \& Posada Tabares, 2013). Por ello algunas investigaciones buscan encontrar nuevos tratamientos para la inflamación (Kumar, Bajwa, Kuldeep, \& Kalia, 2013), en donde se emplean modelos in vivo e in vitro que permiten validar nuevas moléculas o plantas con potencial antiinflamatorio.

Un modelo in vitro utilizado para la investigación de compuestos antiinflamatorios es el de estabilidad de la membrana del eritrocito, que induce la hemólisis con solución salina hipotónica o calor y evalúa la capacidad que tienen los agentes antiinflamatorios de evitar dicha hemólisis, mediante la estabilización de la membrana eritrocitaria, y se les correlaciona con un efecto similar a nivel de la membrana lisosomal (Gaona Fernández, 201 1; Mercy Margaret et al., 2013). Este modelo se ha utilizado en la mayoría de los procedimientos preliminares de evaluación antiinflamatoria (Anilkumar \& Johny, 2015; Mohamed Saleem et al., 2011) y es empleado para evaluar diversas sustancias con posible actividad antiinflamatoria (Kardile, Mahajan, Shaikh, Goyal, \& Patil, 2016).

Un ejemplo de ello es Cuscuta jalapensis Schltdl., planta perteneciente a la familia Convolvulaceae, cuya distribución es cosmopolita. Algunas de estas plantas son arbóreas y otras arbustivas, con flores que descuellan por su aspecto infundibuliforme. La mayoría de las convolvuláceas se encuentran en hábitats soleados y abiertos, mientras que muy pocas sobreviven en bosques muy sombreados. El género Cuscuta se caracteriza porque posee tallos anaranjados y/o amarillos, además de que son plantas parásitas (Oxelman, Kornhall, Olmstead, \& Bremer, 2005; Rzedowski Rotter \& Calderón de Rzedowski, 2005). Se ha determinado que las cuscutas tienen cualidades diuréticas y laxantes; también se han empleado para controlar la tos, afecciones bronquiales y problemas de vías respiratorias; la decocción se utiliza como cicatrizante y en el tratamiento de afecciones hepáticas (Buck, 1969; Múlgura, 1969).

En un trabajo se evaluó la actividad antiinflamatoria de semillas de C. chinensis Lam en ratas y se determinó que ejercen un efecto antiinflamatorio (Liao et al., 2014). Por lo anterior y considerando que es factible que plantas de la misma familia pueden tener propiedades farmacológicas similares, se abre la posibilidad de investigar a $C$. jalapensis y validar su propiedad antiinflamatoria. En este sentido, reportes verbales refieren que $C$. jalapensis (figura 1) es empleada con fines medicinales para tratar el dolor $e$ inflamación.

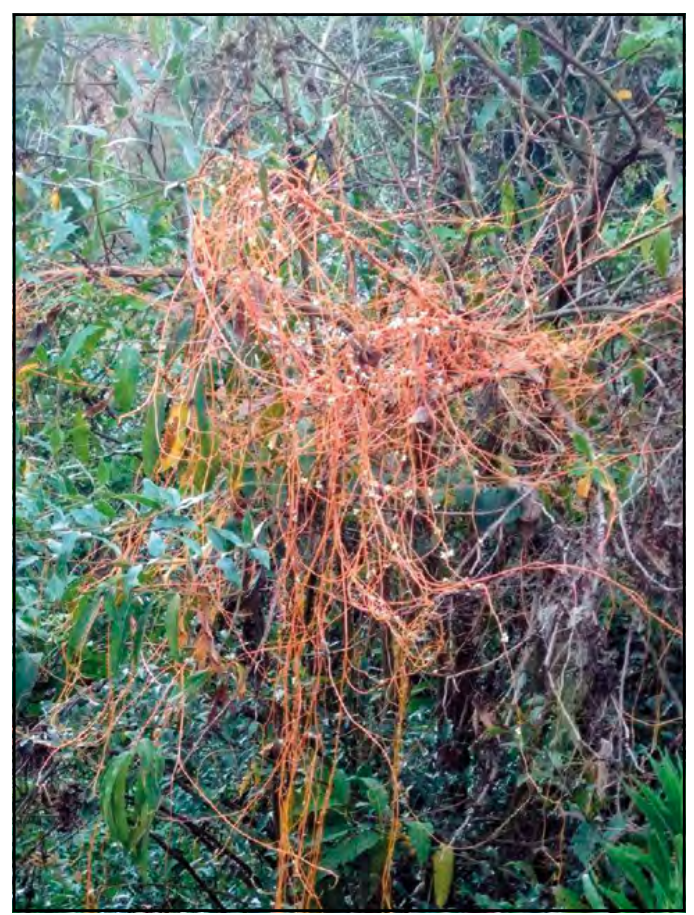

Figura 1. C. jalapensis Schltdl. Fotografía de los autores. 
IIVESTIGACIÓn Y CIERCIA DE LA UחIVERSIDAD AUTÓNOTH DE AGUASCALIERTES
Dado que existen pocos estudios científicos sobre $C$. jalapensis que avalen o refuten sus propiedades curativas y considerando que empíricamente es utilizada por pobladores de la Sierra Nororiental del estado de Puebla, es importante realizar investigaciones que validen sus propiedades medicinales y/o toxicológicas; el presente artículo muestra un estudio in vitro de la capacidad antiinflamatoria de los extractos etanólico y hexánico de C. jalapensis.

\section{MATERIALES Y METODOS}

\section{Obtención del material vegetal}

El material vegetal que se utilizó fue recolectado en la localidad de Tezhuatepec, en el municipio de Atempan, Puebla, cuyas coordenadas geográficas son las siguientes: $19^{\circ} 50^{\prime} 48^{\prime \prime}$ Norte $97^{\circ} 26^{\prime} 42^{\prime \prime}$ 'Occidental (INEGI, 2016). Los ejemplares recolectados fueron utilizados en fresco.

\section{Preparación de los extractos}

El material vegetal (300 g) se maceró durante 7 días con hexano a temperatura ambiente, se separó por filtración y al mismo material se le adicionó etanol y se dejó macerar por un periodo similar. Ambos extractos fueron concentrados con un rotaevaporador a presión reducida y temperatura baja $\left(40-45^{\circ} \mathrm{C}\right)$ hasta obtener los extractos secos, que fueron disueltos en solución salina hipotónica a concentraciones de 50, 100, 200 y $400 \mu \mathrm{g} / \mathrm{ml}$ para su evaluación antiinflamatoria.

\section{Tamizaje fitoquímico}

Para cada uno de los extractos de C. jalapensis se disolvió $1 \mathrm{~g}$ en $100 \mathrm{ml}$ de su disolvente madre (etanol o hexano), para detectar la presencia de diversas familias de metabolitos secundarios como saponinas, taninos, esteroides, quinonas, chalconas, auronas, cumarinas, flavonoides, alcaloides y triterpenoides, los cuales fueron identificados por pruebas coloridas (Cseke et al., 2006).

\section{Actividad antiinflamatoria in vitro}

La actividad de estabilización de la membrana del eritrocito fue evaluada mediante el uso de una solución hipotónica y calor como agentes hemolíticos de acuerdo con el método propuesto por Shinde et al. (1999) y modificado por Sikder et al. (2011). Se emplearon $5 \mathrm{ml}$ de sangre humana, la cual fue centrifugada a 3000 r.p.m. durante $10 \mathrm{~min}$; posteriormente se obtuvo el paquete globular RBC (red blood cells), con el cual se preparó una solución a $10 \%$ v/v de la suspensión de RBC.

\section{Hemólisis inducida con solución salina hipotónica} Para el experimento se empleó una mezcla de reacción que consistió en colocar $0.5 \mathrm{ml}$ de la solución a $10 \%$ de RBC, $1 \mathrm{ml}$ de buffer de fosfato $\mathrm{pH}$ 7.4 y $1 \mathrm{ml}$ de solución salina hipotónica $(0.3 \% \mathrm{p} / \mathrm{v})$. A dicha mezcla se le agregó $1 \mathrm{ml}$ de los extractos a las concentraciones 50, 100, 200, $400 \mu \mathrm{g} / \mathrm{ml}$. Como control negativo se empleó un tubo con la mezcla de reacción al que se le adicionó $1 \mathrm{ml}$ de solución salina isotónica en lugar de los extractos. Para el control farmacológico se empleó la mezcla de reacción y 1 $\mathrm{ml}$ de indometacina preparada con solución salina isotónica a una concentración de $100 \mu \mathrm{g} / \mathrm{ml}$.

Todos los tubos fueron incubados a $37^{\circ} \mathrm{C}$ por 30 min, posteriormente se centrifugaron a 3000 r.p.m. durante $20 \mathrm{~min}$. Los ensayos se realizaron por triplicado y fueron leídos en un espectrofotómetro UV-VIS a $560 \mathrm{~nm}$ para calcular el contenido de hemoglobina, el cual fue usado como un indicativo del grado de hemólisis (a mayor hemoglobina mayor hemólisis).

\section{Hemólisis inducida con calor}

Para esta prueba se empleó la misma mezcla de reacción descrita anteriormente $11 \mathrm{ml}$ de cada una de las siguientes soluciones; RBC a $10 \%$, buffer de fosfato $\mathrm{pH}$ 7.4) a la cual se le adicionó $1 \mathrm{ml}$ de cada una de las diferentes concentraciones ensayadas de ambos extractos (grupos experimentales). Como control negativo se empleó solamente la mezcla de reacción con $1 \mathrm{ml}$ de solución salina isotónica en lugar de los extractos. De manera similar al experimento anterior, el control farmacológico fue indometacina en concentración de $100 \mu \mathrm{g} / \mathrm{ml}$ con la mezcla de reacción. Todas las muestras fueron realizadas por triplicado e incubadas a $57^{\circ} \mathrm{C}$ por un periodo de 30 min y centrifugadas a 2500 r.p.m. durante $5 \mathrm{~min}$. Se obtuvieron las absorbancias en un espectrofotómetro UV-VIS a $560 \mathrm{~nm}$. Para ambas pruebas (hemólisis inducidas por solución salina hipotónica y calor) se determinó el porcentaje de hemólisis sobre RBC (EC. 1) y se calculó el porcentaje de estabilización de la membrana (Ec. 2) de acuerdo con las siguientes ecuaciones.

\section{Análisis estadístico}

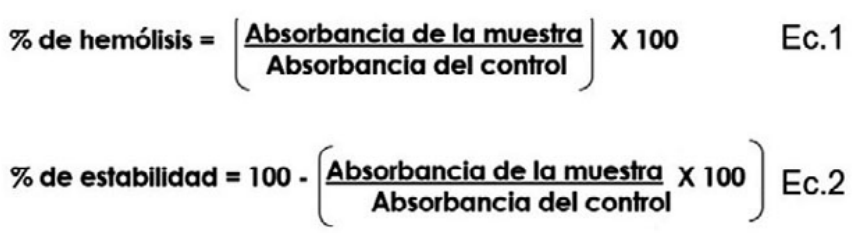


Tabla 1

Tamizaje fitoquímico de los extractos de C. jalapensis Schltdl.

\begin{tabular}{lcc}
\hline \multicolumn{1}{c}{ Familia de metabolitos } & Etanólico & Hexánico \\
\hline Alcaloides & $(+)$ & $(+)$ \\
Saponinas & $(+)$ & $(-)$ \\
Taninos & $(+)$ & $(-)$ \\
Quinonas & $(-)$ & $(-)$ \\
Triterpenos & $(-)$ & $(-)$ \\
Flavonoides/Flavononas & $(+)$ & $(-)$ \\
Chalconas y auronas & $(-)$ & $(-)$ \\
Cumarinas & $(+)$ & $(-)$ \\
Esteroides & $(-)$ & $(-)$ \\
\hline
\end{tabular}

Nota: Resultado positivo (+), resultado negativo (-).

Elaboración propia.

Los datos fueron evaluados mediante análisis de varianza (ANOVA) de una vía para grupos independientes teniendo como factor los tratamientos y cuando $p \leq 0.05$ se empleó la prueba de Tukey como post-hoc. Los resultados se presentan como el promedio \pm el error estándar.

\section{RESULTADOS}

\section{Análisis fitoquímico}

De acuerdo con el tamizaje fitoquímico, se determinó la presencia de las siguientes familias de metabolitos secundarios, en el extracto etanólico: alcaloides, saponinas, taninos, flavonoides/flavonas y cumarinas. En el extracto hexánico sólo fueron encontrados alcaloides. Los resultados para cada extracto se muestran en la tabla 1.

\section{Efecto antiinflamatorio in vitro}

\section{Porcentaje de hemólisis inducida con solución hipotónica}

Al analizar los resultados obtenidos, en relación con el porcentaje de hemólisis inducida con solución salina hipotónica, el ANOVA mostró diferencias estadísticamente significativas entre los grupos $[F(9,20)=$ 379.986; $p<0.001$ ]. La prueba post-hoc indicó que las distintas concentraciones de los extractos y la indometacina disminuyeron $\left({ }^{*} p<0.001\right)$ el porcentaje de hemólisis con respecto al grupo control (CTRL), el cual fue considerado como $100 \%$ de hemólisis. Se determinó que la menor hemólisis se presentó en el extracto etanólico (ET) y la indometacina (IND) con valores por debajo de 5\%; por otra parte, en el extracto hexánico $(\mathrm{HX})$ la hemólisis fue mayor a $5 \%$ a concentraciones de $50,100,200 \mu \mathrm{g} / \mathrm{ml}$ y de $32 \%$ en la concentración de $400 \mu \mathrm{g} / \mathrm{ml}$. Todos los valores del porcentaje de hemólisis obtenidos con el extracto hexánico fueron mayores al control farmacológico indometacina $\left({ }^{* *} p<0.001\right)$. Esto se encuentra en la figura 2.

\section{Porcentaje de estabilidad}

Al analizar el porcentaje de estabilidad de la membrana se encontraron diferencias estadísticamente significativas entre los grupos $\left[F_{(9,2)}=379.975 ; p<\right.$ 0.001 ], la post-hoc indicó que en ambos extractos las concentraciones probadas aumentaron el porcentaje de estabilidad en comparación con el grupo control, en el que se obtuvo $0 \%$ de estabilidad ( ${ }^{*} p<$ $0.001)$.

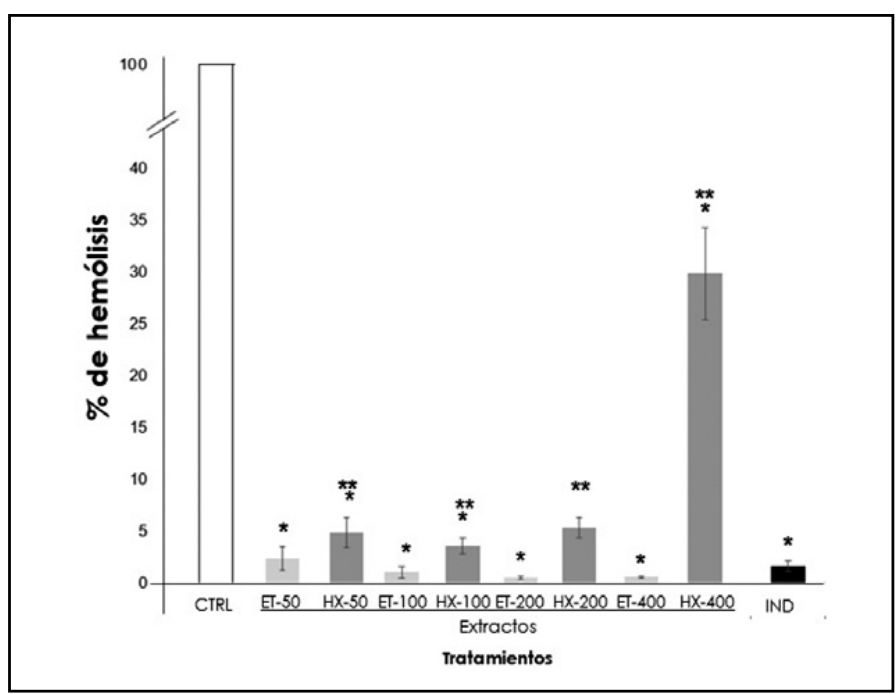

Figura 2. Porcentaje de hemólisis, la cual disminuyó por efecto de los extractos etanólico y hexánico. El extracto etanólico y la indometacina tuvieron valores similares y menores al resto de los grupos ensayados $[F(9,20)=379.986 ; p<0.001]$.

Elaboración propia. 
IIVESTIGACIÓn Y CIERCIA DE LA UNIVERSIDAD AUTÓNOMH DE RGUASCALIERTES
El extracto etanólico mostró porcentajes similares a los del control farmacológico, con valores superiores a $90 \%$. En contraste, las diferentes concentraciones del extracto hexánico tuvieron una estabilidad menor comparado con la indometacina ( ${ }^{* *} p$ $<0.001)$. Finalmente, el menor porcentaje de la variable se obtuvo con la concentración de $400 \mu \mathrm{g} / \mathrm{ml}$ del extracto hexánico, cuyo valor fue aproximadamente de $70 \%$. Esto puede observarse en la figura 3.

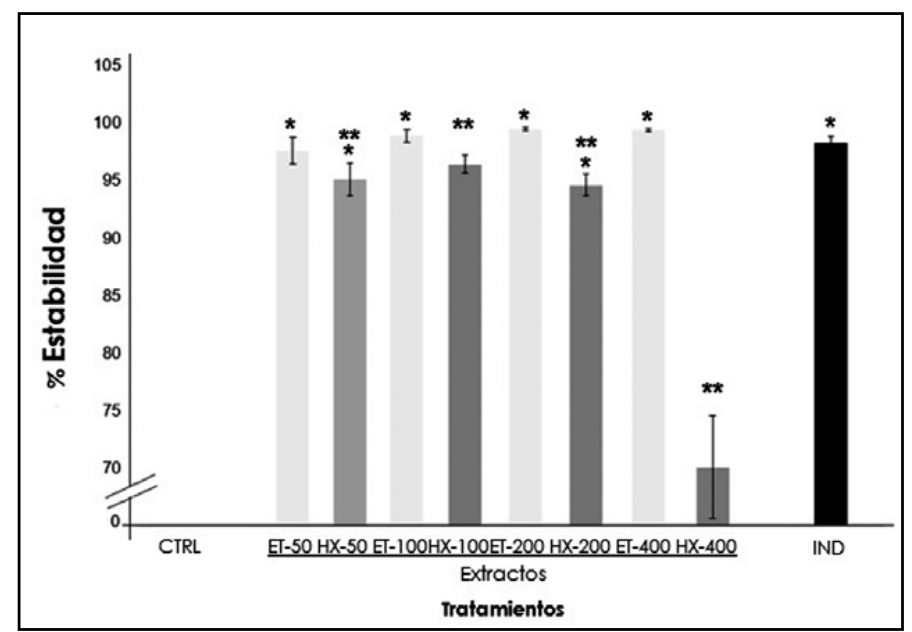

Figura 3. Porcentaje de estabilidad de la membrana por efecto de la administración de los extractos etanólico y hexánico. La mayor estabilidad se obtuvo con el extracto etanólico y fue similar a la indometacina $[F(9,20)=379.975 ; p<0.001]$.

Elaboración propia.

\section{Porcentaje de hemólisis inducida con calor}

Al analizar los resultados obtenidos de esta variable, el ANOVA indicó diferencias significativas $\left[F_{(9,20)}=\right.$ 37.645; $p<0.001$ ], la prueba de Tukey mostró que los extractos (etanólico y hexánico) y la indometacina tuvieron valores significativamente más bajos comparados con el control, donde se obtuvo $100 \%$ de hemólisis $\left({ }^{*} p<0.001\right)$. Las diferentes concentraciones de ambos extractos tuvieron valores de hemólisis menores a $90 \%$. La indometacina mostró $95 \%$ de hemólisis y fue mayor a lo obtenido con las diferentes concentraciones evaluadas de ambos extractos $\left({ }^{* *} p<0.001\right)$. Esto puede consultarse en la figura 4.

\section{Porcentaje de estabilidad}

Finalmente, al analizar el porcentaje de estabilidad para la hemólisis inducida con calor, el ANOVA indicó que existieron diferencias estadísticamente significativas $\left[F_{(9,20)}=37.645 ; p<0.001\right]$. La prueba post-hoc mostró que al evaluar el porcentaje de esta variable se determinó que las concentraciones ensayadas de ambos extractos (etanólico yhexánico)

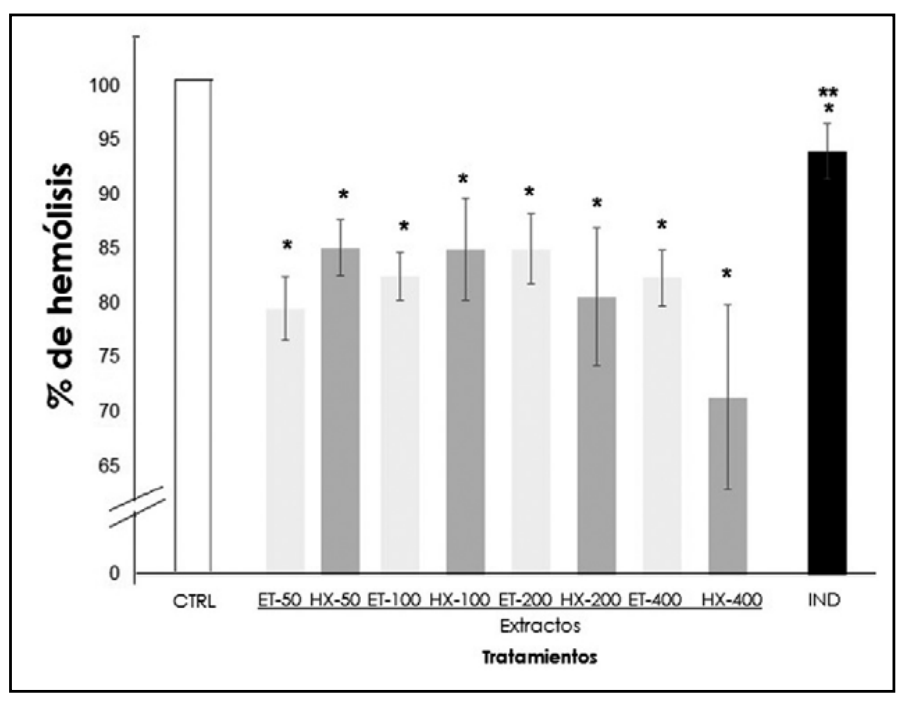

Figura 4. Porcentaje de hemólisis, la cual disminuyó por efecto de los extractos etanólico y hexánico en comparación con la indometacina, cuya hemólisis fue mayor a la obtenida con los extractos $[F(9,20)=37.645 ; p<0.001]$.

Elaboración propia.

y la indometacina aumentaron el porcentaje de estabilidad de la membrana del eritrocito en relación con el control, cuya estabilidad fue de $0 \%\left({ }^{*} p<\right.$ $0.001)$. Ambos extractos mostraron porcentajes de estabilidad estadísticamente similares, mientras que la indometacina tuvo un porcentaje de estabilidad (5\%) más bajo en relación con ellos (**p $<0.001$ ), como puede verse en la figura 5.

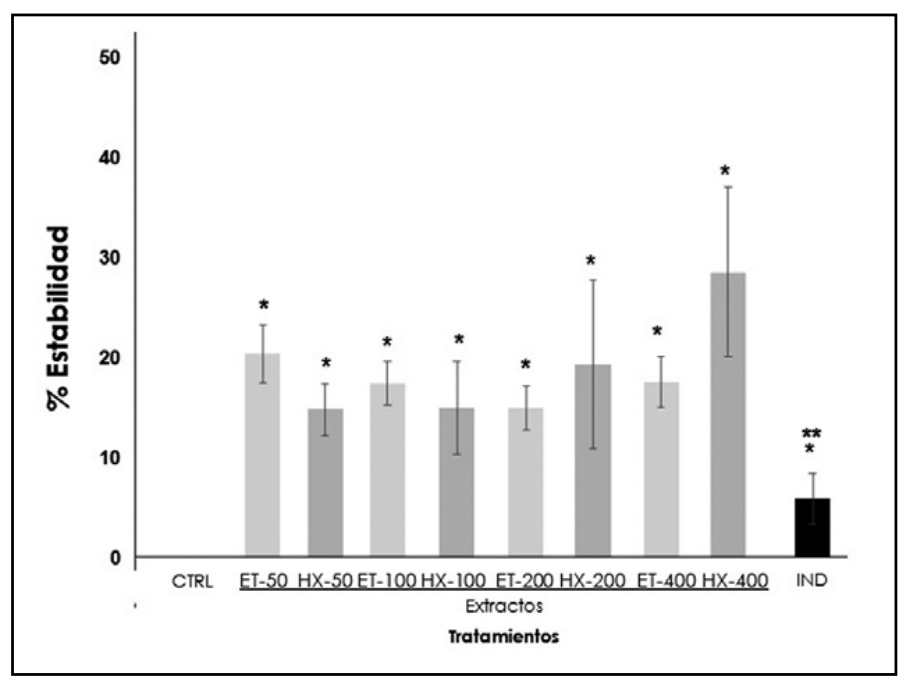

Figura 5. El porcentaje de estabilidad aumentó de manera similar por efecto de la administración de los extractos etanólico y hexánico y su efecto fue mayor al de la indometacina $[F(9,20)=$ 37.645; $p<0.001]$.

Elaboración propia. 
DISCUSIÓN

Uno de los modelos empleados para evaluar efectos antiinflamatorios in vitro se realiza partiendo de que las enzimas lisosomales son liberadas durante procesos inflamatorios, por lo que algunos mecanismos de respuesta conllevan la estabilización de la membrana lisosomal, lo que evita la liberación de dichas enzimas que pueden ocasionar activación de factores y procesos inflamatorios (Kardile et al., 2016; Mercy Margaret et al., 2013). La membrana de los eritrocitos es análoga a la membrana lisosomal; por tanto, evitar la ruptura de la membrana del eritrocito se considera como efecto antiinflamatorio in vitro, de esta manera aquellas sustancias que inhiben la hemólisis también evitan y/o protegen a la membrana lisosomal y en este modelo de estabilidad de la membrana del eritrocito es considerado como efecto tipo antiinflamatorio (Kardile et al., 2016). En este modelo los agentes antiinflamatorios disminuyen el porcentaje de hemólisis y aumentan el porcentaje de estabilidad de la membrana, esto quiere decir que a mayor hemólisis menor estabilidad de la membrana $y$, por consiguiente, un menor efecto antiinflamatorio y viceversa.

Por otra parte, se han realizado evaluaciones para encontrar compuestos útiles en el tratamiento de enfermedades inflamatorias; para ello son empleados diferentes modelos in vivo e in vitro en donde se trata de simular la inflamación, uno de ellos se basa en la inflamación producida por la liberación de histaminas generada por el rompimiento de la membrana lisosomal, lo cual da lugar a una inflamación en el área lesionada (Mercy Margaret et al., 2013; Susunaga-Notario et al., 2014).

Los resultados de nuestro trabajo indicaron que ambos extractos de $C$. jalapensis modificaron las variables evaluadas de manera similar a agentes antiinflamatorios, tal es el caso de la indometacina, fármaco antiinflamatorio que se empleó para este estudio. Por consiguiente, en la hemólisis inducida con solución salina el extracto etanólico tuvo un efecto similar al antiinflamatorio control, ya que redujo el porcentaje de hemólisis y aumentó el porcentaje de estabilidad de la membrana. Lo anterior se traduce como un potencial efecto antiinflamatorio igual al que produjo la indometacina.
Por el contrario, en el extracto hexánico se encontró un efecto antiinflamatorio menor, puesto que hubo mayor hemólisis, lo que tuvo como consecuencia una baja estabilidad de la membrana en relación con el extracto etanólico y con la indometacina. En contraste, en la hemólisis inducida con calor los resultados mostraron que ambos extractos disminuyeron de manera similar la hemólisis, con una mayor estabilización de la membrana eritrocitaria con un efecto antiinflamatorio mejor al de la indometacina para esta prueba.

El efecto antiinflamatorio in vitro en el extracto etanólico de C. jalapensis se atribuye a la presencia de flavonoides, si se considera que en otras plantas, como la Ipomoea batatas, los compuestos fenólicos son los responsables del efecto estabilizador de la membrana (efectos antiinflamatorios in vitro) (Mercy Margaret et al., 2013). También los alcaloides podrían estar implicados en dicho efecto, lo que explicaría la estabilidad mostrada por el extracto etanólico y hexánico, ya que en diversas plantas estos son los compuestos activos responsables de la actividad antiinflamatoria (Barbosa-Filho et al., 2006; Souto et al., 2011), cuyo mecanismo está asociado a su capacidad antioxidante (Torres Cruz, Soto Ojeda, Palomino Asencio, \& García Hernández, 2017).

Los resultados obtenidos en la evaluación de la hemólisis producida con solución salina hipotónica y calor, así como la estabilidad de la membrana obtenida con los extractos ensayados, indicaron que C. jalapensis ejerció un efecto protector de la membrana del eritrocito y que únicamente en el caso de la hemólisis con solución hipotónica fue mayor el extracto etanólico comparado con el hexánico. Estos resultados indican que el efecto de los extractos puede ser similar en la membrana lisosomal, lo que evita su ruptura y la liberación de mediadores de inflamación (Mercy Margaret et al., 2013; Susunaga-Notario et al., 2014). Dichos resultados abren las perspectivas para el estudio de extractos de $C$. jalapensis en modelos animales y es posible correlacionar los resultados encontrados en este trabajo con resultados de modelos in vivo. Además, abre la posibilidad de encontrar un uso terapéutico a esta planta que está considerada como parásita y de la que hay pocos estudios sobre sus propiedades farmacológicas. 
CONCLUSIONES

En este trabajo fueron estudiados los extractos etanólico y hexánico de C. jalapensis para determinar su efecto antiinflamatorio. Se determinó mediante el tamiz fitoquímico que los extractos mostraron la presencia de familias de metabolitos relacionadas con efectos antiinflamatorios, como los flavonoides y alcaloides, compuestos bioactivos responsables de dicho efecto en otras plantas evaluadas de manera similar. Ambos extractos mostraron efecto estabilizador de la membrana del eritrocito y sólo en una prueba fue mayor el etanólico con respecto al hexánico; no obstante, el efecto de ambos extractos puede ser interpretado como antiinflamatorio en este modelo in vitro. El presente trabajo abre las perspectivas para realizar estudios de evaluación de C. jalapensis en modelos animales e in silico para poder determinar su potencial farmacológico en el tratamiento de la inflamación.

REFERENCIAS

- Anilkumar, M., \& Johny, J. (2015). Evaluation of in vitro antiInflammatory activity of the methanolic extract of Litsea quinqueflora (Dennst.) Suresh. Journal of Pharmacy and Biological Sciences, 10(2), 32-36.

- Barbosa-Filho, J. M., Piuvezam, M. R., Moura, M. D., Silva, M. S., Batista Lima, K. V., Leitão da-Cunha, E. V., ..., \& Takemura, O. S. (2006). Anti-inflammatory activity of alkaloids: A twentycentury review. Revista Brasileira de Farmacognosia, 16(1), 109-139

- Buck, H. T. (1969). Convolvulaceae. En A. Burkart (Dir.), Flora Ilustrada de Entre Ríos (Argentina) (Vol. 6, pp. 148-194). Argentina: Colección Científica del Instituto Nacional de Tecnología Agropecuaria.

- Cseke, L. J., Kirakosyan, A., Kaufman, P. B., Warber, S. L., Duke, J. A., \& Brielmann, H. L. (2006). Natural Products from Plants (2a. ed.). Boca Raton, FL, US: CRC Press.

- Gaona Fernández, L. A. (2011). Efecto de árnica en un modelo in vitro con citoquinas proinflamatorias y antiinflamatorias. Fase II (Tesis doctoral no publicada). Universidad Nacional de Colombia, Colombia.

- Instituto Nacional de Estadística y Geografía. (2016). Sociodemográfico de México. México: Autor.

- Kardile, M. V., Mahajan, U. B., Shaikh, H. M., Goyal, S. N., \& Patil, C. R. (2016). Membrane stabilization assay for anti-inflammatory activity yields false positive results for samples containing traces of ethanol and methanol. World Journal of Pharmacy and Pharmaceutical Sciences, 5(3), 493-497.

- Kumar, S., Bajwa, B. S., Kuldeep, S., \& Kalia, A. N. (2013). Antiinflammatory activity of herbal plants: A review. International Journal of Advances in Pharmacy, Biology and Chemistry, 2(2), 272-281.

- Liao, J. C., Chang, W. T., Lee, M. S., Chiu, Y. J., Chao, W. K., Lin, Y. C., ..., Peng, W. H. (2014). Antinociceptive and anti-in- flammatory activities of Cuscuta chinensis seeds in mice. The American Journal of Chinese Medicine, 42 (1), 223-242.

- Mercy Margaret, T., Krishna, P., Revathi, B., Eswar Tony, D. Sathish Kumar, M., \& Narendra Babu, A. (2013). Assessment of in vitro anti inflammatory activity of aqueous extract of Ipomoea batatas tubers. Asian Journal of Research in Biological and Pharmaceutical Sciences, 1 (1), 47-53.

- Mohamed Saleem, T. K., Azeem, A. K., Dilip, C., Sankar, C., Prasanth, N. V., \& Duraisami, R. (2011). Anti-inflammatory activity of the leaf extacts of Gendarussa vulgaris Nees. Asian Pacific Journal of Tropical Biomedicine, 1 (2), 147-149.

- Múlgura, M. E. (1969). Cuscutaceae. En A. Burkart (Dir.), Flora llustrada de Entre Ríos (Argentina) (Vol. 6 5a, pp. 195-203). Argentina: Colección Científica del Instituto Nacional de Tecnología Agropecuaria.

- Oxelman, B., Kornhall, P., Olmstead, R. G., \& Bremer, B. (2005). Further disintegration of Scrophulariaceae. Taxon, 54, 41 1-425.

- Rzedowski Rotter, J., \& Calderón de Rzedowski, G. (Eds.). (2005). Flora del bajío y de regiones adyacentes (serie de fascículos). Pátzcuaro, Michoacán, México: INECOL.

- Sánchez, P. T., Sirera, R., Peiró, G., \& Palmero, F. (2008). Estrés, depresión, inflamación y dolor. R.E.M.E. (Revista Electrónica de Motivación y Emoción), 11 (28). Recuperado de http://reme. uji.es/articulos/numero28/article 1/article 1.pdf

- Shinde, U. A., Phadke, A. S., Nair, A. M., Mungantiwar, A. A., Dikshit, V. J., \& Saraf, M. N. (1999). Membrane stabilizing activity-a possible mechanism of action for the anti-inflammatory activity of Cedrus deodara wood oil. Fitoterapia, 70(3), 251-257.

- Sikder, M. A., Rahman, M. A., Kaisar, M. A., Rahman, M. S., Hasan, C. M., \& Rashid, M. A. (2011). In vitro antioxidant, reducing power, free radical scavenging and membrane stabilizing activities of seeds of Syzygium cumini L. Latin American Journal of Pharmacy, 30(4), 781-785. 
InVESTIGACIÓn Y CIERCIR DE

LA UחIVERSIDAD AUTÓnOMA

DE AGUASCALIERTES

- Souto, A. L., Tavares, J. F., Da Silva, M. S., Diniz, M. D. F., De Athayde-Filho, P. F., \& Barbosa Filho, J. M. (2011). Anti-inflammatory activity of alkaloids: An update from 2000 to 2010. Molecules, 16(10), 8515-8534.

- Susunaga-Notario, A. C., Pérez-Gutiérrez, S., Zavala-Sánchez, M. A., Almanza-Pérez, J. C., Gutiérrez-Carrillo, A., Arrieta-Báez, D., ..., Alarcón-Aguilar, F. J. (2014). Bioassay-guided chemical study of the anti-inflammatory effect of Senna villosa (Miller) H. S. Irwin \& Barneby (Leguminosae) in TPA-induced ear edema. Molecules, 19(7), 10261-10278.
- Torres Cruz, E., Soto Ojeda, G. A., Palomino Asencio, L., \& García Hernández, E. (2017). Estudio ab initio de la capacidad antioxidante de una familia de alcaloides imidazólicos versus flavonoides. Investigación y Ciencia de la Universidad Autónoma de Aguascalientes, 25(72), 30-35.

- Velásquez Gómez, S. V., \& Posada Tabares, V. (2013). Actividad anti-inflamatoria in vitro de los extractos y fracciones obtenidas de la corteza interna de Tabebuia chrysantha (JACQ.) G. Nicholson (Tesis doctoral, Universidad Tecnológica de Pereira, Colombia). Recuperada de https://books.google. com.mx/books/about/Actividad_anti_inflamatoria_in_vitro_ de.htmleid=XF1-swEACAAJ\&redir_esc=y 